\title{
OS CADERNOS DE HISTÓRIA DO ESTADO DE SÃO PAULO (2008-2010) ${ }^{1}$
}

\author{
Jémerson Quirino de Almeida \\ Carla Villamaina Centeno
}

\section{RESUMO}

Este artigo tem por objeto a análise dos Cadernos de História do estado de São Paulo, instrumentos didáticos propostos a partir do ano de 2008, pela Secretaria da Educação/SP. Objetiva, por um lado, apreender as funções que exerceram na relação educativa e, por outro, evidenciar as características dos conteúdos veiculados. Como procedimento metodológico elegeu-se uma temática, o Feudalismo, e foram descritos os conteúdos e atividades relacionados nos Cadernos do $6^{\circ}$ ano do ensino fundamental e da $1^{\mathrm{a}}$ série do ensino médio. Para tanto, incorporou-se a categoria organização do trabalho didático compreendendo-a na perspectiva marxista. Decorrem da análise algumas conclusões: 1) O Feudalismo é exposto aos alunos por meio de pequenos trechos documentais, sobressaindo imagens e mapas; 2) As fontes mais importantes são sugeridas e compreendidas como acessórias não garantindo que estas possam ser centrais ao trabalho didático; 3) Não se evidencia a existência de conceitos diferentes acerca do Feudalismo, encontrando-se, inclusive, simplificações conceituais.

Palavras-chave: Ensino de História; Organização do trabalho didático; Manual didático; Cadernos do estado de São Paulo; Feudalismo

\section{CADERNOS DO ESTADO DE SÃO PAULO (2008-2010): analysis from the perspective of the didactic work}

\begin{abstract}
This article focuses on the analysis of the Cadernos do Estado de São Paulo, didactic tools proposed from the year 2008 by the Education Secretary /SP. On the one hand aims grasp the functions it performs in the educational relationship, and secondly, to show the characteristics of the broadcast content. As procedure was elected a thematic: Feudalism and it have been described the content and activities related to this subject, in the 6th year of primary school and the 1 st year of high school. Therefore, was incorporated the organization of didactic work category, including it in the Marxist perspective. Some conclusions could be done by the analysis: 1) Feudalism is exposed to students through small passages documentary, highlighting images and maps; 2) The most important sources are suggested and are understood as secondary, which does not guarantee that they could be central to the didactic work; 3) There is no observation that there may be different concepts about the Feudalism, finding even some misconceptions.

Keywords: History teaching. Organization of the didactic work. Didactic manual, Cadernos do estado de São Paulo. Feudalism
\end{abstract}




\section{Introdução}

Este artigo é parte de um estudo que resultou em dissertação de mestrado sobre o ensino de História da Idade Média, mais especificamente sobre os Cadernos do estado de São Paulo ${ }^{2}$, instrumentos didáticos adotados na rede pública estadual.

No presente texto, buscamos verificar se os Cadernos sofreram o mesmo grau de simplificação a que foram submetidos os demais livros escolares, conforme a análise a ser demonstrada, sob a perspectiva da categoria organização do trabalho didático, formulada por Alves $(2005)^{3}$ e exposta no desenvolvimento deste trabalho.

Os Cadernos do estado de São Paulo passaram a ser utilizados nas salas de aula em todas as escolas públicas estaduais, a partir de 2008. Tais instrumentos foram propostos como material destinado a apoiar os docentes (CADERNO DO PROFESSOR, $1^{\text {a }}$ série volume 4. Ensino Médio, 2009). No entanto, questionamos se essa é a real finalidade desse material ou se os Cadernos são o instrumento central da relação educativa.

Destacamos que as investigações ligadas à área de História e Educação veem, desde a segunda metade do século XX, desenvolvendo análises que tomam os livros escolares como fonte de pesquisa. De acordo com Fernandes (2005), a partir de 1960

o grande clássico e referência para todos os trabalhos que se seguiram foi a obra de Umberto Eco e Mariza Bonazzi, Mentiras que parecem verdades, traduzido em diversos idiomas. No Brasil, o livro As Belas Mentiras: a ideologia subjacente aos textos didáticos, de Maria de Lourdes Deiró Nosella fez escola, sendo ainda hoje referência em qualquer bibliografia sobre livro didático (FERNANDES, 2005, p. 123,124).

O autor complementa que, a partir da década de 1980, houve renovação dos estudos sobre múltiplas temáticas ligadas à análise das edições didáticas, como a História da leitura e do livro no Ocidente:

A partir da década de 80, em parte pela renovação da História Cultural, com as contribuições teóricas advindas da obra de Roger Chartier e Robert Darton que inovaram os estudos acerca da história da leitura no mundo ocidental, houve mudanças de abordagens nas pesquisas relacionadas ao livro didático. Hoje, os trabalhos estão mais direcionados a questões relativas ao uso e apropriação do livro didático por alunos e professores, às práticas de leitura, entre outros. Assim, segundo Alain Choppin, a história da edição escolar constitui, hoje, um dos campos mais promissores da História da Educação e novas questões se colocam para os historiadores, tais como: a relação entre livro didático e a formação de professores; o livro didático e sua interferência no currículo escolar; o uso do livro didático por parte do aluno; sua utilização na educação não-formal; a linguagem e imagem utilizada nos livros didáticos; o perfil sociológico dos autores; o papel das mulheres na elaboração e difusão dos saberes escolares (FERNANDES, 2005. p. 124).

Além dos apontamentos feitos por Fernandes, observam-se outras propostas de análises, como as de Kazumi Munakata (2012) e Célia Cristina de Figueiredo Cassiano (2007), que abordam o livro didático como mercadoria.

Outro ponto que os estudiosos buscam compreender é o fato de que as disciplinas ligadas às ciências humanas, principalmente Geografia e História, com seus respectivos livros didáticos, foram utilizados no ensino escolar como um dos elementos difusores do 
conhecimento oficial ou da visão das classes dominantes. Segundo Fonseca, os manuais "atuam, na verdade, como mediadores entre concepções e práticas políticas e culturais, tornando-se parte importante da engrenagem de manutenção de determinadas visões de mundo" (FONSECA, 1999. p. 204). Muitas pessoas desconhecem a eficácia do livro didático como formador de opiniões, considerando-os como inofensivos ou neutros. Além do que, como observaram Lajolo \& Zilberman (1999), o livro didático é considerado o "primo pobre" da literatura; por isso, acabam esquecidos, abandonados ou jogados fora, após o esgotamento de sua validez ou mudança de nível escolar do aluno.

Existem também pesquisas que se põem a investigar os instrumentos do trabalho didático e seu papel na relação educativa na sociedade burguesa. Buscam, à luz da leitura de autores clássicos e sob a perspectiva marxista, compreender as relações históricas que envolvem a produção e utilização destes recursos didáticos no ambiente escolar utilizando como categoria a organização do trabalho didático. Neste caminho, destacam-se como referência Alves (2004, 2005, 2011, 2012), Alves \& Centeno (2009) Centeno (2010, 2011), Souza (2010), Brito (2012) e Lancillotti (2013) Em nossa pesquisa compactuamos com os referidos autores.

Para aprofundar a análise dos conteúdos optamos por não trabalhar de forma exaustiva todos os conteúdos das obras examinadas, mas por uma temática específica, muito difundida nos textos escolares de História que tratam da Idade Média: o Feudalismo. Nossa escolha parte do fato de que embora no Brasil tenha ocorrido avanço dos estudos no campo da História Medieval, proporcionando uma reabilitação gradual das pesquisas do período, no meio acadêmico ainda existe um distanciamento entre o conhecimento produzido nas universidades e os conteúdos difundidos pelos materiais didáticos.

Para nós, o ponto de partida para compreender o conceito de Feudalismo é entendêlo como uma forma de organização social, ou seja, a maneira como a sociedade se organiza para produzir os meios de sua sobrevivência. Sendo assim, o Feudalismo pode ser entendido como um modo de produção ${ }^{4}$

A análise do modo de produção desde muito tempo foi utilizada para diferir a organização social Antiga da Medieval. Associou-se ao modo de produção da Antiguidade o escravismo e, ao Medieval, o trabalho servil. Nessa perspectiva, a ruptura entre o uso predominante da força de trabalho escrava e o emprego do trabalho servil define o início do Feudalismo.

A literatura especializada revela outras formas de interpretação e questiona se a categoria trabalho pode ser a única chave teórica para compreender a ruptura entre a organização social Antiga e Medieval.

Para Anderson (1989) e Barbero \& Vigil (1978), a Antiguidade predominantemente escravista durou até os séculos II e III, quando se iniciou a transição para o Feudalismo. Tal movimento concluiu-se no século VI, após a instalação dos invasores bárbaros, que impuseram uma nova ordem social (MARES, 1997, p. 11). Sendo assim, a predominância do trabalho servil em detrimento do escravismo denota a ruptura entre a Antiguidade e o início da Idade Média.

Porém, Mares, ao sintetizar o pensamento de Wickham ( MARES, 1997, p. 11), salienta que o escravismo na antiguidade não foi a característica predominante do período. De acordo com o autor, a modalidade de produção Antiga não se definia somente pelo escravismo. Pois, nesse momento, coexistiam diferentes formas de produção ${ }^{5}$, dentre elas o próprio feudalismo. Para ele, a Antiguidade se definiu pela onipresença do Estado. Portanto, a base do sistema Antigo era a tributação e não o escravismo. (MARES, 1997, p. 11). No entanto, questionamos: de onde vinha o tributo, se não da força de trabalho? O trabalho gera o tributo. Contudo, o autor sustenta que, 
En el sistema antiguo predomina el impuesto, fórmula pública de drenaje de excedentes de los libres hacia la clase dirigente que controla el Estado. Por naturaleza, el impuesto es una carga homogénea o equiparable: una misma base impositiva. En el sistema feudal, en cambio, predomina la renta, que es una fórmula privada de drenaje de excedentes de los campesinos dependentes hacia sus señores, que acaparan el poder, y mantienen vínculos limitados y pactados con poderes superiores externos. (MARES, 1997, p. 14).

Segundo Mares, a organização social na Antiguidade se mantinha mesmo durante as crises mediante o papel fundamental desempenhado pelo Estado, seja ele o vasto Império Romano ou as dioceses que outrora se tornaram reinos germânicos, o que era viabilizado pela tributação (MARES, 1997).

Uma observação importante foi apontada por Bloch (1987) e Duby (1994) sobre a Alta Idade Média. De acordo com os autores, o escravismo não deixou completamente de existir com o fim da Antiguidade, pelo menos durante a Alta Idade Média, quando algumas crises acarretaram a utilização deste tipo de força de trabalho; assim como se tem a convicção de que já existiam, na Antiguidade Tardia, formas de produção feudal. (MARES, 1997).

Outro ponto relevante é o fato de um incalculável grupo de pessoas não serem nem escravos e nem servos em fins da Antiguidade e princípios da Idade Média (MARES, 1997). Segundo Mares: "De alguna manera debían ser derivación de lo que Marx e Engels llamaban comunidad primitiva, es decir, colectivos cercanos a la tribu en los cuales la cohesión de grupo, basada en lazos de sangre y formas de vida y organización conjunta del trabajo, era fuerte". (MARES, 1997, p. 13). Esses grupos foram analisados por Wickham nos Alpes italianos, por Barbero e Vigil (1978) nas montanhas Vasco-catábricas, nos Pirineus e nas antigas terras de Leão e Castela, entre outros. (MARES, 1997, p. 13).

Em nosso estudo, acreditamos que a ruptura entre o modo de produção Antigo e o Feudal pode ser observada ao analisarmos as relações sociais que se articularam para prover os meios que possibilitavam a produção e reprodução da vida material imediata ${ }^{6}$. A forma de organização social pertinente ao modo de produção é a chave teórica para a compreensão da ruptura. Contudo o trabalho ${ }^{7}$ é a lente por onde podemos observar e compreender as sociedades; é a categoria mais ampla. É o trabalho que sustenta a sociedade e determina todo o resto. No entanto, devemos ressaltar que esse enfoque nos permite enxergar as formas mais predominantes e mais acabadas das sociedades ocidentais. Toda forma de análise do período medieval sem mediação de seus aspectos é passível de erros. O medievo difere-se de outros momentos históricos, dado a suas especificidades e a complexa conjuntura social, econômica, política e religiosa que não permite observar facilmente elementos universais comuns a todos os povos medievais, ao longo do milenar recorte temporal referente à Idade Média. Diferente do que ocorre em momentos históricos subsequentes, quando elementos do (pré) capitalismo já universalizam as relações sociais.

\section{Livros escolares enquanto instrumento central da relação educativa}

A organização do trabalho didático na escola contemporânea pauta-se na relevante função atribuída aos livros escolares. Essa foi uma das propostas centrais do capitalismo para a escola moderna, consubstanciada em Comenius, no século XVII. Esse pensador formulou com clareza os elementos essenciais para que a escola fosse universalizada, afirmando que sem o instrumento central, os "livros pan-metodicos" (COMENIUS, 2001, p. 535), seria impossível a efetivação desse ideário. Nesse sentido, é fundamental refletirmos 
sobre a proposta de Comenius de "ensinar tudo a todos" e sobre o papel dos instrumentos de trabalho na escola moderna.

Segundo Alves (2004) a Comenius coube dar forma ao que hoje conhecemos como escola moderna.

Comenius está na origem da escola moderna. A ele, mais do que a nenhum outro, coube o mérito de concebê-la. Nessa empreitada, foi impregnado pela clareza de que o estabelecimento escolar deveria ser pensado como uma oficina de homens (ALVES, 2004, p. 81. Grifos no original).

Ao reconhecer as dificuldades de se estender o modelo educativo predominante em seu tempo, devido aos altos custos e ao reduzido número de pessoas hábeis ao trabalho docente, Comenius buscou, no modelo de divisão do trabalho manufatureiro, a solução para o grande impasse que impossibilitava "ensinar tudo a todos". A esse respeito, Alves (2004) sintetiza que:

[...] o educador morávio pressupunha uma organização para a atividade de ensino, no interior da escola, que visava equipará-la á ordem vigente nas manufaturas, onde a divisão do trabalho permitia que diferentes operações, realizadas por trabalhadores distintos, se desenvolvessem de forma rigorosamente controlada, segundo um plano prévio e intencional que as articulava, para produzir mais resultados com economia de tempo, de fadiga e de recursos (ALVES, 2004, p. 83).

A divisão do trabalho, porém, não fora suficiente para colocar em prática a proposta comeniana. Era necessário criar também um instrumento que viabilizasse o trabalho docente. Para isso, Comenius desenvolveu o que ele chamou de "livros pan-metodicos".

Uma só coisa é de extraordinária importância, pois, se ela falta, pode tornar-se inútil toda uma máquina tão bem construída, ou, se está presente, pode pô-la em movimento: uma provisão de livros pan-metódicos. Efetivamente, da mesma maneira que, fornecendo o material tipográfico, é fácil encontrar quem possa, saiba e queira utilizar, e quem ofereça qualquer soma para imprimir bons e úteis livros, e quem compre esses livros, de preço acessível e de grande utilidade, assim também seria fácil, uma vez preparados os meios necessários para a pan-didática, encontrar os fautores, os promotores e os diretores de que ela precisa (COMENIUS, 2001, p. 535).

Deste modo, a preparação do instrumento de trabalho é o elemento central que possibilitaria colocar a escola em funcionamento. A metodologia de ensino universal, exposta pelo autor, visava o barateamento dos custos e o início de um longo processo de simplificação e de objetivação do trabalho didático que culminou no modelo adotado pelas escolas na modernidade. Comenius prescreveria, ainda, aos educadores

[...] normas precisas às quais conformem seu trabalho; isso significa que, para seu uso, é preciso escrever livros informativos que indiquem de que modo e quando eles devem agir para não errar. Portanto, os livros didáticos serão de dois tipos: os relativos às coisas (reais) para os estudantes e os informativos para os professores, para que estes sejam capazes de usar os primeiros com rapidez e perfeição (COMENIUS, 2001, p. 365). 
O manual didático deveria resumir um programa de conteúdos informativos, dispôlos em ordem sequencial e condicionar os procedimentos docentes necessários ao seu uso. Enfim, dar a tônica ao trabalho didático. Nesse sentido, Comenius eliminou qualquer possibilidade de uso de livros clássicos e apontou, até mesmo, para o caráter dispensável do próprio mestre: "[...] acima de tudo, desejo e solicito que os assuntos sejam expostos em linguagem familiar e comum, para permitir que os alunos entendam tudo espontaneamente, mesmo sem mestre" (id. ibid, p. 217, grifos nossos).

No Brasil, segundo Alves (2011), o processo de implantação da escola manufatureira ocorreu mais tarde, pois a educação escolar fora influenciada pela Contrarreforma. De fato, os primeiros instrumentos mais especializados, transitórios para os manuais comenianos, foram os compêndios. Começaram a ser adotados no século XIX, nos colégios pombalinos, mais especificamente no Colégio Pedro II:

[...] o compêndio passava a incluir um significado que ia além de sua relação estrita com os textos e os autores clássicos. Isto é, continuava sendo "resumo de uma teoria, ciência, doutrina", mas começava a tornar-se, por sua destinação, "livro, esp. escolar, que enfeixa tal resumo" (Houaiss; Villar, 2001, p. 774). O que se difundiu no Brasil, ao longo do século XIX, foi esse significado do termo compêndio associado à sua utilização na escola e, quanto à autoria, a professores das correspondentes matérias que exerciam o magistério nos principais estabelecimentos escolares do País, em especial no Colégio Pedro II (ALVES, 2011, p. 14).

Progressivamente esses instrumentos foram substituindo os clássicos, os florilégios e as antologias ${ }^{8}$.

A proposta comeniana, de livros mais simplificados, foi introduzida paulatinamente no século XIX no ensino elementar e durante o século XX no ensino secundário, porém, só se tornou hegemônica após a segunda metade deste mesmo século (ALVES \& CENTENO, 2009), (ALMEIDA, 2013), quando as preocupações com a expansão do ensino reclamaram barateamento, especialização e simplificação da educação escolar. Permanecem ainda no século XXI, de forma hegemônica, e centralizam a relação educativa.

\section{Os Cadernos do Estado de São Paulo}

Os Cadernos analisados são parte integrante da Proposta Curricular do Estado de São Paulo e foram incorporados ao ciclo II do Ensino Fundamental e ao Ensino Médio em 2008, durante a gestão da secretária Maria Elena Guimarães Castro, posteriormente substituída por Paulo Renato Souza, durante o governo de José Serra ${ }^{9}$.

Como foi afirmado, iremos verificar se nesse instrumento ocorreu a simplificação dos conteúdos por meio de uma temática, o Feudalismo.

O material analisado é organizado em Caderno do Professor e Caderno do Aluno. Em nossa análise nos deteremos de modo mais específico ao Caderno do Professor pois contém mais informações sobre o trabalho a ser realizado com o aluno, ou seja, conteúdos (respostas às questões, sugestões de atividades e indicações de leituras) que não estão expostas no Caderno do Aluno. Contudo, os Cadernos do aluno serão analisados para demonstração da simplificação já apontada.

Os Cadernos estão disponíveis a todas as séries do Ensino Fundamental, ciclo II, e do Ensino Médio. Para cada ano letivo são designados quatro volumes. De acordo com Maria Inês Fini os, 
Cadernos espelharam-se, de forma objetiva, na Proposta Curricular, referência comum a todas as escolas da Rede Estadual, revelando uma maneira inédita de relacionar teoria e prática e integrando as disciplinas e as séries em um projeto interdisciplinar por meio de um enfoque filosófico de Educação que definiu conteúdos, competências e habilidades, metodologias, avaliação e recursos didáticos (CADERNO DO PROFESSOR. $6^{\mathrm{a}}$ ano volume 4, 2009).

Aos Cadernos da área de História é creditada a autoria de Paulo Miceli, Diego López Silva, Glaydson José da Silva, Mônica Lungov Bugelli e Raquel dos Santos Funari, todos com formação avançada em nível de mestrado e doutorado. A impressão e acabamento do material ficaram a cargo da Esdeva Indústria Gráfica. São organizados de modo cronológico, de acordo com a periodização clássica ${ }^{10}$ - Pré-História, História Antiga, Medieval, Moderna e Contemporânea.

O primeiro volume destinado ao $6^{\circ}$ ano tem início com algumas discussões sobre noções de tempo em História e fontes históricas. Na sequência, trata da "Pré-História e a escrita" e da História da Antiguidade. Os últimos Cadernos do $9^{\circ}$ ano versam sobre a Segunda Guerra Mundial, os conflitos oriundos do pós Segunda Guerra e a "Nova Ordem Mundial" Para o Ensino Médio, propõe-se uma retomada de todo o conteúdo apresentado no Ensino Fundamental ciclo II.

Foram selecionados para a análise os seguintes Cadernos (do aluno e do professor): $7^{\circ}$ ano, volume 1 do Ensino Fundamental, ciclo II, e $1^{\text {a }}$ série, volume 3 do Ensino Médio.

Os Cadernos do Professor e do aluno são organizados em "situações de aprendizagens" para discutir conteúdos inseridos em temáticas, no interior da linha cronológica.

Para cada situação de aprendizagem, no Caderno do Professor, há a orientação de: 1) tempo previsto (número de aulas); 2) conteúdos e temas; 3 ) competências e habilidades; 4) estratégias; 5) recursos e 6) avaliação. Apresentam orientações detalhadas sobre todos os conteúdos e atividades.

Já os Cadernos do Aluno começam diretamente na situação de aprendizagem determinada. Geralmente, com uma pequena introdução, fragmento de texto, análise de imagem/mapa ou diretamente com questões a serem respondidas pelos alunos.

No Caderno do professor encontram-se respondidas todas as questões propostas, tanto discursivas quanto objetivas. Também são encontradas orientações sobre como trabalhar determinado conteúdo, imagens, mapas, etc. Também são indicadas, lições de casa (pesquisas, exercícios ou leituras) e na seção Para saber mais são sugeridas referências de livros ou sites, que também estão repetidos nos Cadernos do Aluno. Ao final de cada volume faz-se referência às obras e documentos citados. Por fim, reserva-se um pequeno espaço cerca de uma página - para que o aluno sintetize o que aprendeu ao longo da situação de aprendizagem.

Os conteúdos, de modo geral, são apresentados em pequenos textos que variam de uma a duas páginas no Caderno do professor e de 10 a 15 linhas no Caderno do aluno. Praticamente todas as imagens presentes no Caderno do professor também estão dispostas no Caderno do aluno. De acordo com recomendações sugeridas em cursos de capacitação oferecidos pela Secretaria de Educação do Estado de São Paulo (ALMEIDA 2013, p. 109), o material do professor deve ser lido previamente pelo docente, de modo a auxiliá-lo na preparação de sua aula. Já o aluno deve ler os conteúdos e discuti-los com o professor. As questões devem ser respondidas pelos alunos em sala de aula. Todas as atividades propostas devem ser cobradas pelo professor ao realizar a correção em sala de aula. O mesmo 
procedimento cabe às demais atividades - lições de casa, pesquisas etc. - realizadas fora do período de aula.

Haja vista as informações apresentadas, submetemos os Cadernos aos seguintes questionamentos: 1) Qual atenção foi dada ao Feudalismo? 2) Quanto à interpretação utilizada os autores explicitam teoria? 3) Com os Cadernos de História, houve avanços do ponto de vista do trabalho didático? 4) São apresentados nesse instrumento seções que trabalham com fontes históricas (quais são as fontes)?

O Feudalismo é apresentado no Caderno destinado ao $7^{\circ}$ ano, volume 1 . Nesse mesmo volume, também são abordados os temas: As Cruzadas, O Renascimento Comercial e Urbano e $\mathrm{O}$ renascimento Cultural e Científico.

A situação de aprendizagem 1, intitulada Feudalismo, em suas relações econômicas, políticas e religiosas se inicia no Caderno do professor definindo que:

A Europa feudal era um mundo rural em que a riqueza repousava na terra e a sociedade era dominada pelos senhores feudais, que possuíam, ao mesmo tempo, poder econômico e político. A concessão do feudo e o compromisso de suserania e vassalagem são dois elementos fundamentais para entender o Feudalismo e a sociedade que se organizou na Europa Ocidental entre os séculos IX e XIV e que se desenvolveram a partir das estruturas do mundo romano e germânico, desde o processo das migrações bárbaras e do fim do Império Romano do Ocidente (CADERNO DO PROFESSOR, $7^{\circ}$ ano volume 1, 2009. p.9).

Os recursos de leitura, apontados para o professor trabalhar com o aluno são: "enciclopédias, livros de apoio didático, paradidáticos e dicionário, mídias eletrônicas [...]" (CADERNO DO PROFESSOR, $7^{\circ}$ ano volume 1, 2009. p.10).

A primeira proposta de situação de aprendizagem deste Caderno é a representação de um feudo por meio da montagem de um painel ilustrado que deve ser elaborado pelos alunos, em grupos (CADERNO DO PROFESSOR, $7^{\circ}$ ano volume 1. 2009, p.9). O tempo previsto é de quatro aulas. A primeira delas é designada à sondagem e sensibilização. Nessa aula, o professor deve estimular os alunos a formular hipóteses sobre o período denominado de Idade Média, sobre o que é feudo e quem seriam seus habitantes. Para tanto, recobram o conteúdo trabalhado no ano anterior sobre "as migrações dos povos bárbaros e a crise do Império romano do Ocidente". De acordo com o material

Os estudantes devem expor aqui suas representações sobre o conceito de Feudalismo, sendo provável que eles o associem às representações relacionadas a filmes de cavaleiros, princesas e bruxas. Pode ser também que o associem a trevas, ou a outras características negativas (CADERNO DO PROFESSOR, $7^{\circ}$ ano volume 1.2009. p.10).

Na segunda aula, dá-se início à elaboração do painel ilustrado. Recomenda-se que o professor explique aos alunos

[...] que os documentos são a expressão do passado, fonte para o historiador e instrumento que permite acessar o passado por meio das próprias testemunhas - embora fragmentárias -, proporcionando o ensejo de exercitar-se no trabalho de investigação. Os documentos escritos que conservamos do passado, contudo, não são a história, mas instrumentos válidos para construí-la [...] (CADERNO DO PROFESSOR, $7^{\circ}$ ano volume 1, 2009. p.11). 
A partir de então é requerido que o professor leia com os alunos um extrato de texto ${ }^{11}$ creditado a Afonso $\mathrm{X}^{12}$, o sábio. Nesse texto, o referido autor define o que é feudo e apresenta suas principais características.

Feudo é o benefício dado pelo senhor a algum homem porque se tornou seu vassalo e lhe fez homenagem de ser-lhe leal, tornou este nome da fé que deve o vassalo guardar ao senhor. São duas as formas de feudo: uma é a outorga, uma vila, ou castelo, ou outra coisa que se continua um bem de raiz e este feudo não pode ser tomado do vassalo a não ser se falecer o senhor com o qual tratou ou se fizer algum erro pelo qual o deva perder [...]. Outra maneira é o chamado feudo de câmara; este se faz quando o rei doa maravedis [moeda castelhana] a algum vassalo seu, todo ano em sua câmara, e este feudo pode o rei cancelar quando quiser (AFONSO X, in: PEDREROSÁNCHES, 2000 apud CADERNO DO PROFESSOR, $7^{\circ}$ ano volume 1 , 2009. p.11).

Na sequência, após a leitura do documento, é recomendado que o professor oriente os alunos na seleção de algumas palavras, como "feudo", "benefício", "vassalagem" e "outorga", para que pesquisem seu significado (CADERNO DO PROFESSOR, $7^{\circ}$ ano volume 1, 2009. p.11). O Caderno do professor oferece a definição de cada um dos termos. Chama-nos a atenção a definição de feudo presente nesse Caderno, concebido como "o tipo predominante de organização econômico-social durante a Idade Média, também chamada de senhorio ou domínio". A definição difere da concebida por Afonso X, que sustenta a definição de feudo como "o benefício dado pelo senhor a algum homem porque se tornou seu vassalo e lhe fez homenagem de ser-lhe leal [...]" (CADERNO DO PROFESSOR, $7^{\circ}$ ano volume 1, 2009. p.11). Para nós, a definição exposta no caderno do professor é superficial e equivocada, pois nela se confunde o termo Feudalismo com feudo, que, por seu turno, também não deve ser entendido como sinônimo de senhorio ou domínio ${ }^{13}$.

Mais à frente observa-se um pequeno extrato elaborado por Raquel dos Santos Funari, uma das autoras da área de História, intitulado: A origem das palavras feudo $e$ feudalismo, que apresenta uma visão diferente e mais elaborada das que anteriormente foram expostas.

A palavra 'feudal', que vem de fief, feodum, de origem germânica ou celta, designa o direito de desfrutar qualquer bem, geralmente terra, mas que podia ser também o direito de cobrar uma taxa de pedágio para passar em uma ponte ou pelo uso de um moinho ou lagar, ou ainda um título ou cargo que desse algum privilégio. $\mathrm{O}$ feudo não era uma propriedade como conhecemos nos dias de hoje, mas pode ser considerado uma forma de posse sobre alguns bens reais. Tudo o que se relacionava a ele passou a ser chamado de Feudalismo. A palavra 'feudalismo' significa um conjunto de características econômicas, culturais, filosóficas, artísticas, religiosas, entre outras, ligadas ao feudo (CADERNO DO PROFESSOR, $7^{\circ}$ ano volume 1, [200-] p.11).

Os extratos se encontram presentes no Caderno do aluno. Em seguida ao texto de Funari, são propostas três questões. Questão 1. A partir das ideias do texto, crie uma definição, com suas palavras, para a palavra feudal. Questão 2. Segundo o texto, quais são os quatro exemplos de bens relacionados ao feudo? Questão 3. Elabore uma definição para a palavra feudalismo. Ora, se nem o material foi capaz de definir os conceitos feudo e 
feudalismo, de modo plausível, e com as fontes necessárias e suficientes, como um aluno do $7^{\circ}$ ano poderia fazê-lo?

Como atividade, o Caderno também propõe a observação de uma gravura que representa uma cidade medieval, além da leitura e análise de outro pequeno texto: $O$ funcionamento do sistema de três campos nos feudos, de autoria de Raquel dos Santos Funari. A autora expõe ainda a definição de Manso, Terra comunal, Castelo, Moinho, Aldeia $e$ Vila. Pouco à frente, outro extrato documental é apresentado: Vassalagem e investidura (séculos XII e XIII) de Galberto Brugense ${ }^{14}$, demonstrando as relações de suserania e vassalagem no Feudalismo.

$\mathrm{Na}$ terceira e quarta aulas, os alunos devem organizar a preparação do painel ilustrado sobre o feudo. Além do painel são sugeridas cinco questões para avaliação, sendo duas discursivas e três objetivas.

Como proposta de situação de recuperação ${ }^{15}$ é recomendada uma atividade ${ }^{16}$. São indicadas, ainda, quatro referências de livros e um filme para ampliar a perspectiva do professor e do aluno sobre o tema ${ }^{17}$.

O Feudalismo volta a ser trabalhado no $3^{\circ}$ volume da $1^{\mathrm{a}}$ série do Ensino Médio. A organização do material do Ensino Médio segue a mesma composição estabelecida para o Ensino Fundamental. Trata-se basicamente de uma retomada e proposta de aprofundamento dos conteúdos anteriormente trabalhados no Ciclo II do Ensino Fundamental. Vale pontuar que os textos para o ensino médio continuam mais diminutos (resumidos e simplificados) do que os indicados para o ensino fundamental e os conteúdos fragmentados em pequenos tópicos.

A temática é a quarta e última situação de aprendizagem do período Medieval. Sociedade Feudal - características sociais econômicas, políticas e culturais tem o tempo previsto de "duas ou três aulas". De início, o professor é orientado a relembrar junto aos alunos o conteúdo estudado a esse respeito. O estudo visa reconhecer e problematizar aspectos definidores da organização social feudal "centrado em duas tarefas: uma de leitura de imagens e outra de síntese de um documento" (CADERNO DO PROFESSOR. $1^{\text {a }}$ série do Ensino Médio. $3^{\circ}$ volume, 2009. p.29).

Para a leitura de imagens é sugerido: "um conjunto de imagens de um livro das horas $^{18}$ no Caderno do Aluno [...]" (CADERNO DO PROFESSOR. $1^{\text {a }}$ série do Ensino Médio. $3^{\circ}$ volume, 2009. p.27, grifos nossos). No Caderno do aluno, a situação de aprendizagem propõe a observação de seis imagens oriundas do Livro das Horas do Duque de Berry, destacando o caráter cronológico relacionados às horas canônicas ou litúrgicas e solicita que analise a representação dos trabalhadores retratados (CADERNO DO ALUNO. $1^{a}$ série do Ensino Médio. $3^{\circ}$ volume, 2009. p.26).

Também é suscitada a análise de texto e de outra imagem. A imagem representa um clérigo, um cavaleiro e um camponês de autoria de "Jairo Souza Design" (CADERNO DO ALUNO, $1^{\text {a }}$ série do Ensino Médio. $3^{\circ}$ volume, 2009. p.29), possivelmente contratado para desenhar a representação, pois não há qualquer identificação com obras ou imagens mais representativas ou reconhecidas pelo meio acadêmico. $\mathrm{O}$ caderno faz menção à sociedade dividida em três grupos na visão de Adalbéron de Laon, do século XI. No material do professor é exposto um extrato de 12 linhas do livro $O$ feudalismo de Hilário Franco Junior (1985) que expõe a interdependência entre os três grupos medievais na visão de Adalbéron de Laon. O presente extrato não está presente no Caderno do aluno. O Caderno do professor faz ressalvas sobre a ordem social exposta por Adalbéron de Laon

Observe que essa é uma representação de um contexto de profundas mudanças sociais no começo do século XI, sendo esse modelo de tripartição 
social representativo dos conflitos sociais do período e dos interesses sobretudo dos grupos sociais mais abastados, para os quais era conveniente qualquer mudança na ordem das coisas (CADERNO DO PROFESSOR. $1^{\text {a }}$ série do Ensino Médio. $3^{\circ}$ volume, 2009. p.37).

Ainda que o Caderno do professor cite a fonte de Franco Junior nas orientações, encontramos a afirmação de que o texto pertence ao bispo de Adalberon de Laon: "analise a imagem a seguir, acompanhada do texto do bispo Adalberon de Laon" (CADERNO DO PROFESSOR. $1^{\text {a }}$ série do Ensino Médio. $3^{\circ}$ volume, 2009. p.36). Na verdade o texto é uma interpretação de Franco Junior acerca dos escritos do referido bispo.

Para a avaliação, foram propostas cinco questões, duas discursivas e três questões objetivas.

O único texto - existente no Caderno do aluno é um fragmento de 6 linhas retirado de uma questão da COMVEST/ Vestibular UNICAMP de autoria de Marc Bloch acerca das invasões bárbaras e do surgimento do feudalismo.

Como proposta de situação de recuperação, é sugerida uma pesquisa sobre o papel da terra ou da Igreja na Idade Média. São recomendados dois livros introdutórios sobre o Feudalismo para ampliar a perspectiva do professor e do aluno sobre o tema ${ }^{19}$.

\section{CONSIDERAÇÕES FINAIS}

Os Cadernos do estado de São Paulo foram propostos como material destinado a apoiar os docentes. Mas observamos que a finalidade do mesmo é orientar todos os passos a serem tomados pelo docente em sala de aula para mediar a relação educativa. Do ponto de vista do trabalho didático, o manual procura simplificar as operações realizadas pelo professor. É extremamente detalhado e tenta cobrir todas as etapas do trabalho de ensino. O Caderno do aluno é um roteiro de conteúdos, em que as situações de aprendizagem são consonantes aos planos de aula propostos no Caderno do professor, com menos conteúdo evidentemente. Portanto, esse material tem por função organizar o trabalho didático de acordo com uma proposta metodológica específica adotada pelo Estado.

Quanto à versão veiculada, verificamos que os Cadernos são ecléticos, na medida em que incorporam diferentes tipos de interpretação sobre um mesmo conceito sem explicitação clara dessa questão e com conceitos simplificados. Como exposto na análise que realizamos do Caderno destinado ao $7^{\circ}$ ano, volume 1 , em relação ao conceito de feudo e feudalismo. Apontam de forma genérica que pode haver versões diferentes para as diversas fontes, mas não demonstram isso na versão incorporada, ao interpretar um mesmo conceito.

O fato é que não há leituras consistentes e de longo alcance nos Cadernos e sim fragmentos. O que se observa, de fato, é uma valorização excessiva de imagens e mapas. Essa ocorrência foi apontada por Souza como "tendência bastante problemática nos dias de hoje, pela usurpação massiva, no manual didático, do espaço do texto escrito" (SOUZA, 2010, p. 136) O material, na maior parte das vezes, só indica leituras mais consistentes para ampliar o conhecimento ou para recuperação. Mesmo que os livros estejam disponíveis na biblioteca da escola, cabe ao professor utilizá-los ou não. Não há garantia de que sejam incorporadas ao trabalho didático de forma sistemática.

Sustentamos que o material é consonante à anacrônica configuração comeniana do trabalho didático e, portanto, deve ser superado.

Como apontado pela teoria que nos embasa, carecemos construir uma nova organização do trabalho didático (ALVES, 2005), não excludente, mas acima de tudo que visa resgatar e dispor democraticamente o conhecimento sólido, culturamente significativo. Alguns caminhos para realizarmos essa árdua tarefa podem ser a conciliação entre a 
produção humana de outros tempos (como os livros clássicos) junto às novas tecnologias (como a internet), pesquisas sistemáticas realizadas por docentes e discentes promovendo a produção de conhecimento nas escolas. Esses instrumentos não podem figurar como sugestões ou recursos para ampliar a perspectiva do professor ou do aluno. Nem mesmo aparecer como pequenos fragmentos. Os clássicos, as fontes originais, precisam ser os instrumentos. É necessário, também, repensar toda a organização manufatureira, como os espaços, a disposição das salas, a divisão do tempo em disciplinas hierarquizadas, o tempo destinado à leitura e propor trabalhos coletivos de orientação com professores de diferentes áreas, em espaços apropriados. Por fim, repensar toda a organização escolar que propicie as condições concretas, visando oferecer aos jovens o conhecimento significativo.

\section{REFERÊNCIAS}

AMARAL, Ronaldo. A Antiguidade Tardia nas discussões historiográficas acerca dos períodos de translatio. Alétheia - Revista de estudos sobre Antigüidade e Medievo, volume único, Janeiro/Dezembro de 2008.

ANDERSON, Perry. Passagens da antiguidade ao feudalismo. Trad. TelmaCosta. Ed. $3^{\circ}$. Porto: Afrontamento, 1989.

ALMEIDA, Jémerson Quirino de. O ensino de história da idade média no Brasil: dos compêndios aos Cadernos do estado de São Paulo. 2013. 148f. Dissertação (Mestrado em Educação) - Programa de Pós-graduação em Educação, Linguagem e Sociedade da Universidade Estadual de Mato Grosso do Sul, Unidade Universitária de Paranaíba, Paranaíba, 2013.

ALVES, Gilberto Luiz. A produção da escola pública contemporânea. 2. ed. Campinas: Autores Associados, 2004.

O trabalho didático na escola moderna: formas históricas. Campinas, SP: Autores Associados, 2005.

. Organização do trabalho didático: a questão conceitual. Acta Scientiarum, Education (Online), v. 34, p. 169-178, 2012.

Textos escolares e manuais didáticos comenianos. Texto apresentado na I Jornada de Estudos Sobre a Organização do Trabalho Didático. Campo Grande, 2011.

ALVES, Gilberto Luiz; CENTENO, Carla Villamaina. A produção de manuais didáticos de história do Brasil: remontando ao século XIX e início do século XX. Revista Brasileira de Educação, v. 14, n. 42, p. 469-487, set./dez. 2009.

BARBERO, Arbilio; VIGIL, Marcelo. La formación del feudalismo en la Península Ibérica, Barcelona, 1978.

BARROS, Cesar Mangolin de. O conceito de modo de produção. Disponível em < http://cursohumanidades.files.wordpress.com/2010/02/curso-marxismo-aula-o-conceitode-modo-de-producao-2010-texto-do-prof-cesar-mangolin-de-barros.pdf $>$ acesso em $16 /$ set/2012.

BEZERRA NETO, Luiz. BEZERRA, Maria C. dos Santos. JACOMELI, Mara Regina Martins. Currículo Escolar em São Paulo: uma proposta para discussão. Revista educação e Cidadania. Vol. 8, n. 1. jan/jun.2009.

BLOCH, Marc Leopold Benjamin. A Sociedade Feudal. $2^{\text {a }}$ ed. Lisboa: Edições 70, 1987. 
BRITO, Silvia Helena Andrade de. O ensino de sociologia e a organização do trabalho didático no Colégio Pedro II (1925-1945). Revista Brasileira de História da Educação, v. 12, p. 95-124, 2012.

CADERNO DO PROFESSOR, $6^{\circ}$ ano volume 4. Ensino Fundamental ciclo II, 2009.

CADERNO DO ALUNO, $6^{\circ}$ ano volume 4. Ensino Fundamental ciclo II, [200-].

CADERNO DO PROFESSOR, $7^{\circ}$ ano volume 1. Ensino Fundamental ciclo II, 2009.

CADERNO DO ALUNO, $7^{\circ}$ ano volume 1. Ensino Fundamental ciclo II , [200-]

CADERNO DO PROFESSOR, $1^{\text {a }}$ série volume 4. Ensino Médio, 2009.

CADERNO DO ALUNO, $1^{\text {a }}$ série volume 4. Ensino Médio, [200-].

CASSIANO, Célia Cristina de Figueiredo. O mercado do livro didático no Brasil: da criação do Programa Nacional do Livro Didático (PNLD) à entrada do capital internacional espanhol (1985- 2007). 2007. 252 p. Tese de doutorado - Pós-graduação Educação: História, Política e Sociedade da PUC - SP. São Paulo, 2007.

CENTENO, Carla Villamaina. O manual didático Projeto Araribá História no município de Campo Grande, Revista HISTEDBR On-line, número especial, p. 20-35, mai. 2010- ISSN: $1676-2584$.

COMENIUS, Iohannis Amos. Didáctica Magna. Trad. Joaquim Ferreira Gomes. Lisboa: Fundação Calouste Gulbenkian, 2001.

DUBY, Georges. As três ordens ou o imaginário do feudalismo. Trad. Maria Helena Costa Dias. Lisboa: Editorial Estampa, 1994.

Engels, Friedrich. A origem da família, da propriedade privada e do Estado. 17. ed. Rio de Janeiro: Bertrand Brasil, 2005.

FERNANDES, José Ricardo Oriá. O livro didático e a pedagogia do cidadão: o papel do Instituto Histórico e Geográfico Brasileiro no ensino de História. Revista de História. [13]; João Pessoa, jul./ dez. 2005.

GUERREAU, Alain. Feudalismo. In: .; SCHIMITT, J-C (Coord.). Dicionário Temático do Ocidente Medieval. Bauru: EDUSC; São Paulo: Imprensa Oficial do Estado, 2002. p. 437- 455.

FRANCO JR., Hilário. O Feudalismo. São Paulo: Editora Brasiliense, 1997.

LAJOLO, M. e ZILBERMAN, R. A Formação da Leitura no Brasil. São Paulo: Ática, 1999.

LANCILLOTTI, Samira Saad Pulchério. Manuais de psicologia como instrumentos de trabalho utilizados na formação dos professores paulistas (1920-1940). Cadernos de História da Educação (UFU. Impresso), v. 12, p. 29-44, 2013.

LOMBARDI, José Claudinei. Periodização na História da Educação Brasileira: Aspecto polêmico e sempre provisório Revista HISTEDBR On-line, Campinas, n.32, p.200-209, dez.2008 - ISSN: 1676-2584.

MARES, Josep María Salrach. Europa em La transición de la Antiguedad al Feudalismo: el marco general de la historia y la panorámica de la historiografía relativa al período. VII Semana de Estudios medievales. Nájera, 1997. In: http://dialnet.unirioja.es/servlet/articulo?codigo=554316, Acesso em: 20.12.2014. 
MARX, Karl. O capital: Crítica da Economia Política. Vol. I, Tomo I. Coleção os economistas. Trad. Régis Barbosa e Flávio R. Kothe. São Paulo: Abril Cultural, 1983.

MUNAKATA, Kasumi. O livro Didático como mercadoria. Disponível em< http://www.scielo.br/pdf/pp/v23n3/04.pdf> acesso em 12/jan/2015.

NOGUEIRA, Isabel Candolo. Betsabéia e os Livros de Horas Medievais. ANPUH - XXV Simpósio Nacional de História - Fortaleza, 2009.

REIS, J. E. Território, legislação e monarquia no reinado de Alfonso X, o Sábio (1252 1284). Tese de Doutorado - Faculdade de Ciências e Letras de Assis - Universidade Estadual Paulista. Assis, 2007, 250f. : il.p.12.

SANFELICE, José Luiz. MINTO, Lalo Watanabe. LOMBARDI, José Claudinei.

Política e financiamento da Educação em São Paulo. Revista educação e Cidadania. Vol. 8, n. 1. jan/jun.2009.

SEE/SP. Secretaria de Estado da Educação de São Paulo. Proposta Curricular do Estado de São Paulo: História. São Paulo: SEE. 2008.

SOUZA, Ana A. Arguelho de. Manuais didáticos: formas históricas e alternativas de superação. A organização do trabalho didático na história da educação. BRITO, Silvia Helena Andrade de [et al.]. (orgs.). Campinas, SP: Autores Associados: HISTEDBR, 2010.

\footnotetext{
${ }^{1}$ Esta pesquisa contou com o apoio da CAPES.

${ }^{2} \mathrm{O}$ trabalho analisou a relação entre o ensino de História da Idade Média e os livros escolares brasileiros. De modo específico, foi observado como se deu o processo de fragmentação e simplificação dos conteúdos presentes nos livros destinados ao uso escolar no Brasil, desde o século XIX, o que desembocou na confecção e emprego dos atuais Cadernos utilizados no estado de São Paulo. Ver ALMEIDA, Jémerson Quirino de. $O$ ensino de história da idade média no Brasil: dos compêndios aos Cadernos do estado de São Paulo. 2013. 148f. Dissertação (Mestrado em Educação) - Programa de Pós-graduação em Educação, Linguagem e Sociedade da Universidade Estadual de Mato Grosso do Sul, Unidade Universitária de Paranaíba, Paranaíba, 2013. Bolsista da CAPES.

3 a) ela é, sempre, uma relação educativa que coloca, frente a frente, uma forma histórica de educador, de um lado, e uma forma histórica de educando(s), de outro;

b) realiza-se com a mediação de recursos didáticos, envolvendo os procedimentos técnico-pedagógicos do educador, as tecnologias educacionais e os conteúdos programados para servir ao processo de transmissão do conhecimento,

c) e implica um espaço físico com características peculiares, onde ocorre. (ALVES, 2005, p. 10-11, grifos do autor.)

${ }^{4}$ De acordo com Nicos Poulantzas o modo de produção constitui um objeto abstrato-formal que deve ser entendido como uma formação social historicamente determinada, isto é, um todo social - no sentido mais vasto - num dado momento de sua existência histórica" (POULANTZAS apud BARROS, 2010).

${ }^{5}$ Segundo Mares, nesse momento o próprio escravismo se manifestava de diferentes formas. Não apenas em "grandes domínios" de "exploração direta", como também, em "pequenos domínios" cuja exploração era de "tipo médio". Nas grandes propriedades de "exploração direta" os escravos poderiam viver amontoados e trabalharem a terra conjuntamente, como também, poderiam ser divididos em grupos reduzidos e habitar pequenas cabanas e cultivar parcelas diminuídas de terra. No caso da exploração de "tipo médio", os escravos viviam em habitações anexas as casas dos donos (MARES, 1997, p. 14).

${ }^{6}$ No prefácio a primeira edição da obra A origem da Família, da propriedade privada e do Estado, em 1884 , Friedrich Engels sustenta que "Segundo a concepção materialista, o fator determinante, em última instância, na história é a produção e reprodução da vida imediata que, no entanto, se apresentam sob duas formas. De um lado, a produção de meios de subsistência, de produtos alimentícios, habitação e instrumentos necessários para isso. De outro lado, a produção do mesmo homem, a reprodução da espécie. A ordem social em que vivem os
} 
homens de determinada época histórica e de determinado país esta condicionada por esses dois tipos de produção: de um lado, pelo grau de desenvolvimento do trabalho e, de outro, pela família" (ENGELS, 2005, p. 14).

${ }^{7}$ Em $O$ Capital Marx define que: “Antes de tudo, o trabalho é um processo entre o homem e a Natureza, um processo em que o homem, por sua própria ação, media, regula e controla seu metabolismo com a Natureza. Ele mesmo se defronta com a matéria natural como uma força natural. Ele põe em movimento as forças naturais pertencentes à sua corporalidade, braços e pernas, cabeça e mão, a fim de apropriar-se da matéria natural numa forma útil para sua própria vida. Ao atuar, por meio desse movimento, sobre a Natureza externa a ele e ao modificá-la, ele modifica, ao mesmo tempo, sua própria natureza. Ele desenvolve as potências nela adormecidas e sujeita o jogo de suas forças a seu próprio domínio”. (MARX, 1983. p. 149)

${ }^{8}$ Segundo Alves (2012, p. 6): “Antologia tem o sentido literal de 'estudo das flores' ou 'coleção de flores escolhidas', podendo também ser traduzida como 'florilégio'. No caso, refere-se à 'coleção de textos em prosa e/ou em verso, ger. de autores consagrados, organizada segundo tema, época, autoria etc.'. Expressão sinônima é, ainda, 'seleta', entendida como 'conjunto de trechos literários selecionados' ( Houaiss; Villar, 2001, p. 239, 1360 e 2539)".

${ }^{9}$ Entre os estudos que versam sobre essa transição podemos destacar: As políticas para a educação pública do Estado de São Paulo de Maria C. M. Sarno e José M. Cancelliero (2009), no qual os autores abordam o desenvolvimento das políticas públicas estaduais de 1983 a 2009. Currículo Escolar em São Paulo: uma proposta para discussão, de Luiz Bezerra Neto, Maria Cristina dos Santos Bezerra e Mara R. M. Jacomeli (2009), em que se propõe discutir criticamente a proposta paulista para Ciências Humanas. Política $e$ financiamento da Educação em São Paulo de José Luiz Sanfelice, Lalo W. Minto e José C. Lombardi (2009), que analisam as principais tendências ideológicas e políticas presentes na reforma paulista, procurando apontar caminhos para sua superação.

${ }^{10}$ No artigo Periodização na História da Educação Brasileira: Aspecto polêmico e sempre provisório, José Claudinei Lombardi afirma que, "O debate sobre a periodização é permanente e recorrente no âmbito da História (e certamente também da História da Educação). Apesar da aparência de constituir-se num tema datado, tradicional e superado, trata-se, ao contrário, de discussão que se mantém atual e, além de útil e necessária à delimitação do objeto de investigação, expressa e pressupõe a concepção histórica que o pesquisador adota na sua prática e em seu fazer cientifico e didático. É a periodização que expressa o entendimento de como ocorrem as mudanças estruturais, globais e profundas - as transformações históricas e como se dá a transição de um período para o outro" (LOMBARDI, 2008. p. 201).

${ }^{11}$ Trata-se da seguinte referência: Afonso X, o sábio. Las siete partidas. Madrid: Boletim Oficial del Estado, 1985, 3v. Ed. Fac-símile: Salamanca, 1555. p. 65. In: PEDRERO-SÁNCHES, Maria Guadalupe. História da Idade Média -textos e testemunhas. São Paulo: Fundação Editora da Unesp, 2000. p. 97-98.

${ }^{12}$ Afonso X, o Sábio (1221-1284) era filho de Isabel de Hohenstaufen, conhecida nos reinos de Castela e Leão como Beatriz da Suábia (1202-1235) e Fernando III, o Santo de Leão e Castela. Foi rei de Castela e Leão de 1252 até sua morte em 284. De acordo com Jaime Estevão dos Reis, "No campo do saber Alfonso X não teve, seguramente, rival entre os seus contemporâneos. intelectual e poeta, cercou-se de artistas, poetas, tradutores, juristas e outros letrados, aos quais encomendou e coordenou uma grandiosa tarefa cultural, que resultou na produção de obras de caráter literário, histórico, científico, artístico e jurídico, sem paralelo em qualquer outra parte da Europa do século XIII. Com justa razão foi chamado de 'o Sábio', e os historiadores contemporâneos atribuem-lhe ainda o título de 'imperador da cultura' e de 'patrono das letras e do saber"'. (REIS, 2007. p. 2013).

${ }^{13}$ A palavra dominium é de origem latina e pode ser traduzida como dominação, porém segundo Guerreau “[...] propomos chamar de dominium uma relação social original constituída pela simultaneidade e unidade de dominação sobre os homens e suas terras" (GUERREAU, 2002. p. 445). Sendo assim, é importante esclarecer que o dominium não indicava apenas bens fixos, embora a terra fosse o benefício mais difundido e comum de feudalização. Bem mais que isso, representava de modo geral os direitos concebidos através dos laços de vassalagem sobre tudo aquilo que pudesse ser feudalizado. Por seu turno, o termo feudo originou-se do beneficium Carolíngio, e não necessariamente corresponde a um bem imóvel, podendo ser em alguns casos um direito, como de cobrar pedágio em uma estrada ou ponte, utilizar um moinho, ou ter um cargo remunerado como, por exemplo, o de cobrador de impostos. (FRANCO JUNIOR. 1997).

${ }^{14}$ Trata-se da seguinte referência: BRUGENSE, Galberto. Vita Karoli Comitis Flandrie. In: M.G.H. Scriptores, t. XII. Hannover, 1856. p. 591. Apud: Espinosa. Op.ct, p. 172. In: PEDRERO-SÁNCHES, Maria Guadalupe. História da Idade Média: textos e testemunhas. São Paulo: Editora da UNESP, 2000. p. 96.

${ }^{15}$ Sugestão de atividades para recuperar aqueles alunos que não tenham atingido os objetivos de apreensão dos conteúdos. 
16 "Oriente os alunos a traçar uma linha do tempo no caderno, demarcando o período que oficialmente corresponde à Idade Média, em seguida, oriente-os a assinalar a Alta Idade Média e a Baixa Idade Média, apresentando suas principais características" (CADERNO DO PROFESSOR, $7^{\circ}$ ano volume 1, n/d. p. 19)

${ }^{17}$ Livros: D’HAUCORT, Grueviéve. A vida na Idade Média. São Paulo: Martins Fontes, 1994. LE GOFF, Jacques. Para um novo conceito de Idade Média. Lisboa: Estampa, 1997. PEDRERO-SÁNCHEZ, Maria Guadalupe. História da Idade Média - textos e testemunhas. São Paulo: Fundação Editora da Unesp, 2000. RIORDAN, James. Rei Artur. São Paulo: Ática,2005. Filme: Merlin e a espada (Merlin and the sword). Direção: Clive Donner, 1985. 94 min.

${ }^{18}$ O correto seria “do Livro das horas". Segundo Isabel Candolo Nogueira (2009): "Na Idade Média a produção de arte no ocidente estava associada à difusão e consolidação do cristianismo que fornecia à arte uma imagética específica, bem como seu sentido e sua finalidade. A representação imagética dos temas bíblicos devia corresponder ao estipulado pelo texto sagrado, assim, a escolha dos elementos constitutivos da representação atrelava-se ao determinado pela narrativa dos episódios [...] O livro de horas, essencialmente um livro de orações para uso secular, foi uma espécie de best-seller medieval que se popularizou em torno do século XIV até, mais ou menos, a segunda metade do século XVI [...] O livro no mundo cristão medieval tinha um valor simbólico como portador da palavra divina, era confeccionado com esmero, com fólios ricamente ornamentados. A pintura em documentos escritos já era utilizada na Antiguidade, mas se tornou uma arte tipicamente medieval com as iluminuras. Até finais do século XII e início do século XIII a Igreja manteve o monopólio na elaboração de manuscritos, mas com o crescimento urbano e a fundação das universidades ateliês laicos de cópia e iluminura vão se instalar nas principais cidades européias diversificando a produção. O termo iluminura designa hoje a arte do manuscrito em seu conjunto, ou seja, a totalidade dos elementos decorativos, bem como as representações figuradas (miniaturas) nele executadas. Entre os manuscritos medievais iluminados voltados à religiosidade pode-se citar: a Bíblia, as Bíblias Moralizadas, os Evangeliários, os Sacramentários e os Saltérios, livros de devoção pessoal que serão posteriormente substituídos pelos livros de horas" (NOGUEIRA, 2009. p. 1,2,3).

${ }^{19}$ FRANCO JUNIOR, Hilário. O feudalismo. São Paulo: Brasiliense, 1985. MICELI, Paulo. O feudalismo. Ed. São Paulo: Saraiva, 2007.

Recebido: fevereiro-15 Aprovado: fevereiro-15 